\title{
Maternal educational level, parental preventive behavior, risk behavior, social support and medical care consumption in 8-month-old children in Malmö, Sweden
}

Elisabeth Mangrio ${ }^{1,2}$, Kristina Hansen $^{1,2}$, Martin Lindström ${ }^{1,2}$, Marie Köhler ${ }^{2}$ and Maria Rosvall ${ }^{1,2^{*}}$

\begin{abstract}
Background: The social environment in which children grow up is closely associated with their health. The aim of this study was to investigate the relationship between maternal educational level, parental preventive behavior, parental risk behavior, social support, and use of medical care in small children in Malmö, Sweden. We also wanted to investigate whether potential differences in child medical care consumption could be explained by differences in parental behavior and social support.
\end{abstract}

Methods: This study was population-based and cross-sectional. The study population was 8 month-old children in Malmö, visiting the Child Health Care centers during 2003-2007 for their 8-months check-up, and whose parents answered a self-administered questionnaire ( $n=9,289$ children).

Results: Exclusive breast feeding $\geq 4$ months was more common among mothers with higher educational level. Smoking during pregnancy was five times more common among less-educated mothers. Presence of secondhand tobacco smoke during the first four weeks of life was also much more common among children with lesseducated mothers. Less-educated mothers more often experienced low emotional support and low practical support than mothers with higher levels of education (>12 years of education). Increased exposure to unfavorable parental behavioral factors (maternal smoking during pregnancy, secondhand tobacco smoke and exclusive breastfeeding <4 months) was associated with increased odds of in-hospital care and having sought care from a doctor during the last 8 months. The odds were doubled when exposed to all three risk factors. Furthermore, children of less-educated mothers had increased odds of in-hospital care $(\mathrm{OR}=1.34(95 \% \mathrm{Cl}: 1.08,1.66))$ and having sought care from a doctor during the last 8 months (OR $=1.28(95 \% \mathrm{Cl}: 1.09,1.50)$ ), which were reduced and turned statistically non-significant after adjustment for unfavorable parental behavioral factors.

Conclusion: Children of less-educated mothers were exposed to more health risks, fewer health-promoting factors, worse social support, and had higher medical care consumption than children with higher educated mothers. After adjustment for parental behavioral factors the excess odds of doctor's visits and in-hospital care among children with less-educated mothers were reduced. Improving children's health calls for policies targeting parents' healthrelated behaviors and social support.

Keywords: Epidemiology, Medical care consumption, Children, Education, Health-related behaviors

\footnotetext{
* Correspondence: Maria.rosvall@med.lu.se

'Department of Clinical Sciences, Malmö, Social Medicine and Health Policy,

Lund University, S-205 02 Malmö, Sweden

Full list of author information is available at the end of the article
} 


\section{Background}

Socioeconomic conditions have been shown to influence the risk of many types of ill health in Sweden. This is manifested as increased mortality and in-hospital care due to accidents and diseases such as cardiovascular disease and lung cancer in lower socioeconomic position (SEP) groups [1,2], while there are smaller differences in out-of-hospital medical care consumption [3]. However, studies on social differences in medical care consumption have been criticized for neglecting or excluding the use of health services by children and young people, despite evidence that people in younger age groups form a significant proportion of all healthcare users [4]. The social patterning of medical care consumption seen in children does not necessarily follow the pattern seen among adults, due to differences in disease patterns and factors such as costs and availability. In Sweden, medical care visits are free for children under the age of 12 years, and the drugs prescribed are subsidized with taxes. Furthermore, there is a well-developed preventive care organization offering regular visits until the child is 5-6 years old, controlling his or her physical and psychological development and administering vaccinations according to a general base program. These consultations are free of charge and optional.

It is widely acknowledged that the social position of the family is closely related to the health risks that small children are exposed to, and so the environment in which children grow up is closely associated with their health $[1,5]$. The family's socioeconomic situation affects the child's health from the very beginning, through the mother's living conditions and health habits during her pregnancy. Parental smoking, short duration of breast feeding and low social support are more common in lower socioeconomic groups, and have all been shown to be associated with increased morbidity in infancy [1,6-12], which in turn might lead to increased medical care consumption. However, to date there are only a few studies on socioeconomic differences in medical care consumption among small children $[13,14]$. To the best of our knowledge, there is no study that has investigated the contribution of differences in parental behavioral factors and social support to socioeconomic differences in medical care consumption. The aim of the present study was to investigate potential differences in parental preventive behavior, risk behavior, social support, and the use of medical care among small children in Malmö, Sweden, by maternal educational level. We also wanted to examine whether potential differences in child medical care consumption by maternal educational level could be explained by differences in parental behavior and social support.

\section{Methods}

\section{Study population}

This study was conducted in Malmö. Malmö is situated in the southwest part of Sweden. It is the third largest town in the country, with a population of about 300000 inhabitants. It is a multiethnic city, with $30 \%$ of its inhabitants having been born abroad [15]. The study was population-based and cross-sectional. The study population comprised 8-month-old children from Malmö, who visited the Child Health Care (CHC) centersduring 2003-2007 for their 8-months check-up, and whose parents answered a self-administered questionnaire $(\mathbf{n}=$ 9,289 children; $65 \%$ of those who received the questionnaire). The $\mathrm{CHC}$ centersin Sweden are a well-established organization with a strong tradition, monitoring children's physical and developmental health in order to reduce mortality, morbidity, and disability among babies and young children. The $\mathrm{CHC}$ centers offer base programs including regular visits until the child is 5-6 years old, controlling his or her weight, height, hearing, sight, and physical and psychological development, as well as administering vaccinations according to the base program. Some of the visits are conducted with a nurse, and some with a nurse and a physician. The $\mathrm{CHC}$ centers support and educate parents concerning childcare and child development. The $\mathrm{CHC}$ focus is prevention; visits are voluntary and the consultations are free of charge. As many as $99 \%$ of children aged 0-5 participate [16].

The questionnaire contained approximately 30 questions about issues such as the parents' educational level, country of birth, social support, and the child's medical care consumption and housing. It also included questions about maternal smoking during pregnancy, presence of secondhand tobacco smoke and breastfeeding. The questionnaire was validated and translated into five different languages: Albanian, Arabic, English, SerboCroatian, and Somali [17].

\section{Maternal educational level}

Maternal educational level was based on years of schooling and divided into lower educational level (i.e., 9 years or less), medium educational level (i.e., 10-12 years), and higher educational level (i.e., more than 12 years of education).

\section{Parental and child characteristics}

Parents' country of birth was divided into: both parents born in Sweden, one parent born in Sweden, and both parents born outside Sweden. Low birth weight was defined as $<2500 \mathrm{~g}$, and normal birth weight as $\geq 2500$ g. Number of children at home was assessed through the 
question: "How many children aged 0-18 do you have at home?"

\section{Social support}

Emotional support (given to the parents) was assessed with the question: "Do you have someone who can give you proper personal support to cope with life's stresses and problems?" with answers being classified into high emotional support ("yes, definitely" or "yes, probably") and low emotional support ("not for certain" or "no"). Practical support (given to the parents) was assessed with the question: "Would you be able to get help from someone to look after your child, within the same day?", with answers being classified into low practical support ("not for certain" or "no") and high practical support ("yes, definitely" or "yes, probably").

\section{Preventive behavior \\ Breast feeding, tooth brushing, and participation in parental preventive programs}

Length of breastfeeding was dichotomized into $<4$ and $\geq 4$ months of exclusive breastfeeding. Difficulties with breastfeeding were assessed through the question: "Has the child's mother had any breastfeeding problems?" with response alternatives: "Yes" or "No". The types of breastfeeding problems were further assessed through the question: "If yes, what kind of problem?" with response alternatives: "Difficulties getting milk production started"; "Insufficient breast milk"; "Sore nipples"; "The child had difficulty suckling"; "Other, please specify?". More than one type of problem could be reported. Having brushed the child's teeth was assessed through the question: "If the child has any teeth, have you started to brush them?" with response alternatives of "Yes" or "No". Parental training was assessed through $\mathrm{CHC}$-journals, in which the nurse stated whether or not the parents had taken part in a parental educational program. The parental training program includes information and discussions about issues such as delivery and parenthood.

\section{Risk behavior}

Smoking during pregnancy and secondhand tobacco smoke Maternal smoking during pregnancy was divided into yes and no. Exposure to secondhand tobacco smoke during early life (when the child was 0-4 weeks of age) was divided into no (no exposure at all) and yes (daily exposure, including smoking outside).

\section{Medical care consumption}

Having sought care from a doctor during the last 8 months in addition to the regular $\mathrm{CHC}$-visits was categorized into "Yes" or "No". In-hospital stay was assessed through the question: "Has the child been admitted to hospital during the last 8 months?" with response alternatives of "Yes" or "No".

\section{Statistical methods}

Proportions with 95\% confidence intervals of parental preventive behavior (length of exclusive breastfeeding, tooth brushing, participation in parental educational program), parental risk behavior (maternal smoking during pregnancy and secondhand tobacco smoke), and social support (low emotional support, low practical support) were analyzed in relation to maternal educational level. The odds of medical care consumption, (doctor's visits and in-hospital care), were analyzed in relation to exposure to one, two or three unfavorable parental behavioral factors (exclusive breastfeeding $<4$ months, maternal smoking during pregnancy, and secondhand tobacco smoke) by logistic regression. Logistic regression was further used to analyze the associations between maternal educational level and the child's medical care consumption. Multiple logistic regression analyses were performed in order to adjust the estimated OR for covariates. Model 1 included year, sex, parents' country of birth, low birth weight and number of children at home; model 2 included model 1 with additional adjustment for low emotional support and low practical support; and model 3 included model 2 with additional adjustment for maternal smoking during pregnancy, secondhand tobacco smoke at 0-4 weeks; and length of exclusive breastfeeding. Statistical analyses were performed with version 17.0 of SPSS for Windows. The study was approved by the Regional Ethical Committee, Lund University.

\section{Results}

Table 1 shows the association between maternal educational level and parental preventive behavior. Exclusive breast feeding $\geq 4$ months was more common among mothers with higher levels of education than among less-educated mothers. A similar pattern of association was seen for tooth brushing and participation in parental educational programs. Since it is well-known that participation in parental educational programs might differ depending on whether or not the child is the parents' firstborn child, we repeated the latter analyses among parents with firstborns only. The results showed proportions of $40.8 \%$ among less-educated mothers (i.e., $\leq 9$ years of education), $68.2 \%$ among mothers with 10 12 years of education and $81.8 \%$ among mothers with more than 12 years of education.

Among mothers without breastfeeding problems 83\% exclusively breastfed their child for at least 4 months, while the corresponding proportion among mothers with such problems was $42 \%$. Many of the factors associated with a shorter period of exclusive breastfeeding 
Table 1 Parental preventive behaviour by maternal educational level in 8-month-old children in Malmö, Sweden

\begin{tabular}{llll}
\hline & $\begin{array}{l}\text { Exclusive breastfeeding } \geq \mathbf{4} \\
\mathbf{( \% , 9 5 \% ~ C l )}\end{array}$ & $\begin{array}{l}\text { Tooth brushing } \\
(\mathbf{\%}, \mathbf{9 5 \%} \mathbf{C l})\end{array}$ & $\begin{array}{l}\text { Having taken part of parental education program } \\
(\mathbf{\%}, \mathbf{9 5 \%} \mathrm{Cl})\end{array}$ \\
\hline Maternal educational level & & & \\
\hline$\leq 9$ years of education & $47.7(44.1,51.5)$ & $51.2(47.2,55.1)$ & $36.0(32.7,39.2)$ \\
\hline $10-12$ years of education & $55.5(53.4,57.5)$ & $67.3(65.1,69.5)$ & $52.8(50.8,54.7)$ \\
\hline$>12$ years of education & $67.6(66.2,68.9)$ & $71.9(70.4,73.3)$ & $69.4(68.1,70.6)$ \\
\hline
\end{tabular}

were also more often associated with breastfeeding problems, such as presence of secondhand tobacco smoke at 0-4 weeks, low birth weight, and having been admitted to neonatal care ward after delivery (data not shown). However, there were no differences in the frequency of reported breastfeeding problems between those of low and higher educational level (data not shown).

Although, there was no difference in the frequency of breastfeeding problems according to mother's educational level, the types of problems were different in mothers with different educational levels and the various types of breastfeeding problems also showed clear differences in terms of the effect on length of breastfeeding. Insufficient breast milk was associated with the lowest proportion of exclusive breastfeeding $\geq 4$ months (Figure 1). Various types of breastfeeding problems also differed by maternal educational level (Figure 2).

Table 2 shows the association between maternal educational level and parental risk behavior. Smoking during pregnancy was five times more common among less-educated mothers ( $\leq 9$ years of education) compared to among mothers with a higher level of education $(>12$ years of education). Furthermore, presence of secondhand tobacco smoke during the first 4 weeks in life was much more common among children to less-educated mothers.

Table 3 shows presence of low social support (given to the parents) in relation to maternal educational level. Less-educated mothers more often experienced both low emotional support and low practical support in comparison to mothers with a higher level of education ( $>12$ years of education).

Figure 3 shows the association between exposure to unfavorable parental behavioral factors and child medical care consumption. Increased exposure to unfavorable parental behavioral factors (maternal smoking during pregnancy, secondhand tobacco smoke during 0-4 weeks of age, and duration of exclusive breastfeeding $<4$ months) was associated with increased odds of child medical care consumption (i.e., doctor's visits and inhospital care). The odds were doubled when exposed to all three risk factors (Figure 3).

Table 4 shows the odds ratios of child medical care consumption by maternal educational level. Children of less-educated mothers showed increased odds of having

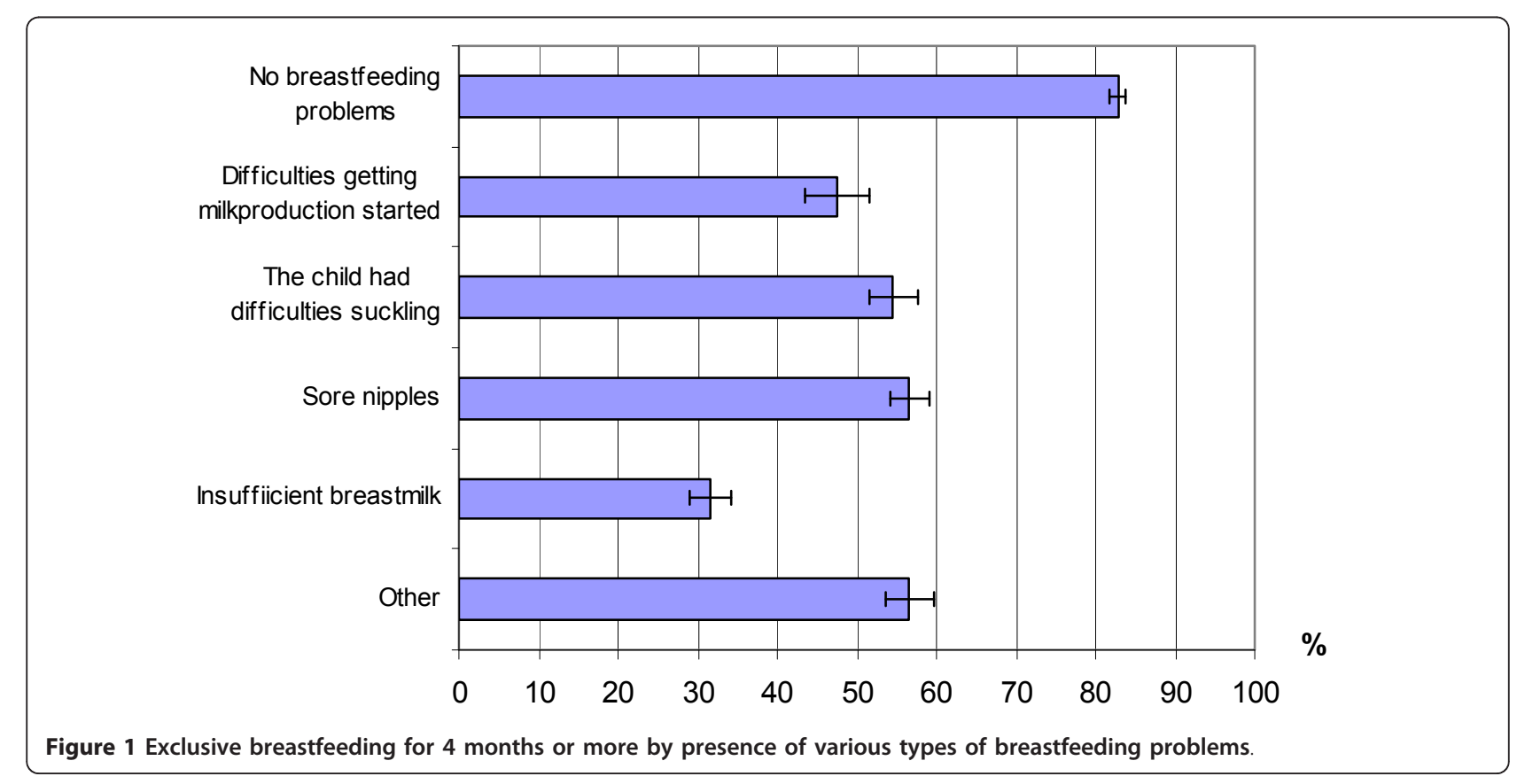




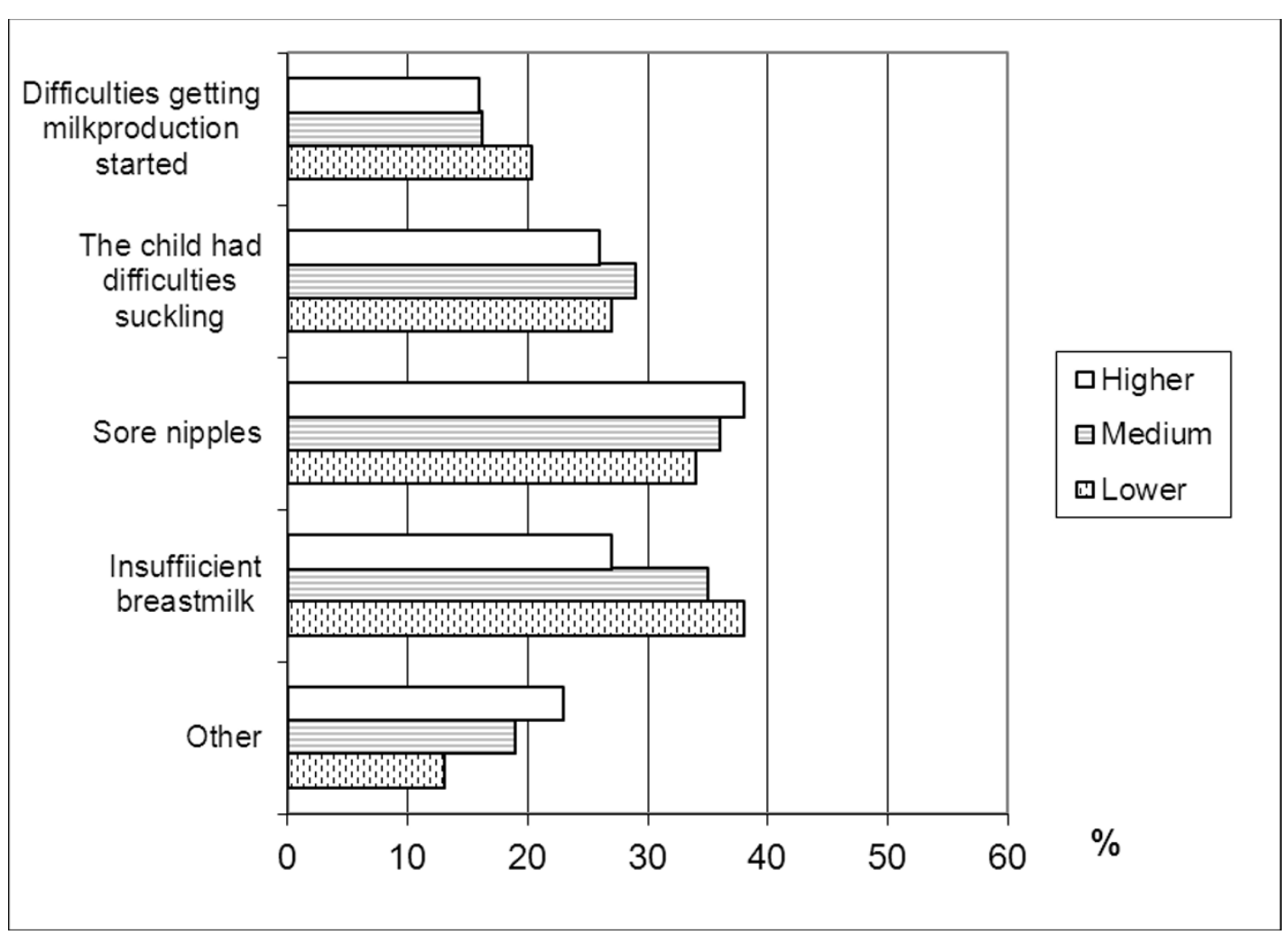

Figure 2 Presence (\%) of various types of breastfeeding problems by maternal educational level. Lower educational level, $\leq 9$ years of education; medium educational level, 10-12 years of education; and higher educational level, > 12 years of education

sought care from a doctor during the last 8 months besides the regular $\mathrm{CHC}$ visits, even after adjustment for year, sex, number of children at home, parents' country of birth and low birth weight (model 1$)$, OR $=1.28$ (95\% CI: $1.09,1.50)$, compared to higher educated mothers ( $>12$ years of education). This association persisted after additional adjustment for low social support (model 2), OR $=1.25$ (95\% CI: 1.06, 1.48), but became statistically non-significant after additional adjustment for maternal smoking during pregnancy, presence of secondhand tobacco smoke during 0-4 weeks of age, and duration of exclusive breast feeding less than 4 months (model 3). A similar pattern of association was seen for in-hospital care with a higher odds of in-hospital care among children to less-educated mothers $(\mathrm{OR}=$ 1.34 (95\% CI: $1.08,1.66))$ for model 1 and $((\mathrm{OR}=1.33$
(95\% CI: 1.06, 1.65)) for model 2. This association turned statistically non-significant in model 3.

\section{Discussion}

The results showed that maternal educational level is closely related to the health risks that small children are exposed to. Children with less-educated mothers were exposed to more health risks, fewer health promoting factors, worse social support, and had a higher medical care consumption than children whose mothers had higher levels of education. After adjustment for parental behavioral factors (maternal smoking during pregnancy, secondhand tobacco smoke during the child's first four weeks of life, and exclusive breastfeeding $<4$ months), the excess odds of doctor's visits and in-hospital care among children with less-educated

Table 2 Parental risk behaviour by maternal educational level in 8-month-old children in Malmö, Sweden

\begin{tabular}{lll}
\hline & $\begin{array}{l}\text { Maternal smoking during pregnancy } \\
(\mathbf{\%}, \mathbf{9 5} \% \mathbf{C l})\end{array}$ & $\begin{array}{l}\text { Exposure to secondhand tobacco smoke at } \mathbf{0} \text { to } \mathbf{4} \text { wks } \\
(\mathbf{\%}, \mathbf{9 5 \%} \mathbf{C l})\end{array}$ \\
\hline Maternal educational level & & $38.6(35.5,41.8)$ \\
\hline$\leq 9$ years of education & $20.6(18.0,23.3)$ & $26.7(25.0,28.3)$ \\
\hline $10-12$ years of education & $12.2(10.9,13.4)$ & $10.7(9.9,11.5)$ \\
\hline$>12$ years of education & $3.6(3.1,4.1)$ & \\
\hline
\end{tabular}


Table 3 Low social support by maternal educational level

\begin{tabular}{lll}
\hline & Low emotional support $\mathbf{( \% , 9 5 \% ~ C l )}$ & Low practical support $\mathbf{( \% , 9 5 \% ~ C l )}$ \\
\hline Maternal educational level & & \\
\hline$\leq 9$ years of education & $35.5(32.4,38.6)$ & $37.1(34.0,40.3)$ \\
\hline $10-12$ years of education & $14.3(13.0,15.6)$ & $21.7(20.1,23.3)$ \\
\hline$>12$ years of education & $9.5(8.7,10.3)$ & $26.8(25.7,28.0)$ \\
\hline
\end{tabular}

mothers were reduced and became statistically nonsignificant.

It is not easy to make international comparisons in medical care consumption due to differences in factors such as availability and fees. A study from Great Britain [18] showed that children and young people living under materially deprived conditions were more likely to be admitted to hospital. However, two other studies, one from Sweden and one from Great Britain, found no socioeconomic differences in the use of health services by children $[4,19]$. According to another Swedish study (published in 2000) among children aged 1-5 years, lesseducated parents were less likely to have paid a visit to a physician when their child had an infection and less likely to have consumed antibiotics, compared to more highly-educated parents [20]. These results are in contrast to the findings in one of our previous studies, published in 2009, where we showed that the odds of small children's use of antibiotics increased as parental educational level decreased [21]. Some of these differences in results might perhaps be related to differences in day care and reduced costs of medical care visits for children. Low educational groups are likely to be more sensitive to the costs of medical care.

The differences in child medical care consumption were reduced after adjustment for parental behavioral factors, i.e., maternal smoking during pregnancy, early exposure to secondhand tobacco smoke, and duration of exclusive breastfeeding $<4$ months. These factors may theoretically be regarded as intermediate factors in the same causal chain and were shown to be associated both with maternal educational level and medical care consumption. There may be different mechanisms underlying the association between such behavioral factors and medical care consumption. Earlier studies have shown breastfeeding to be protective and associated with decreased morbidity in infancy with a lowered incidence of infectious diseases [8,22], asthma [9], overweight [23], and some childhood cancers [10], as well as a better cognitive development [11]. Maternal smoking during pregnancy has been shown to increase the odds for having a child with cleft lip/palate [24], decreased lung function [1], colic pain [25], and meningococcal disease during the first years of life [26]. Maternal

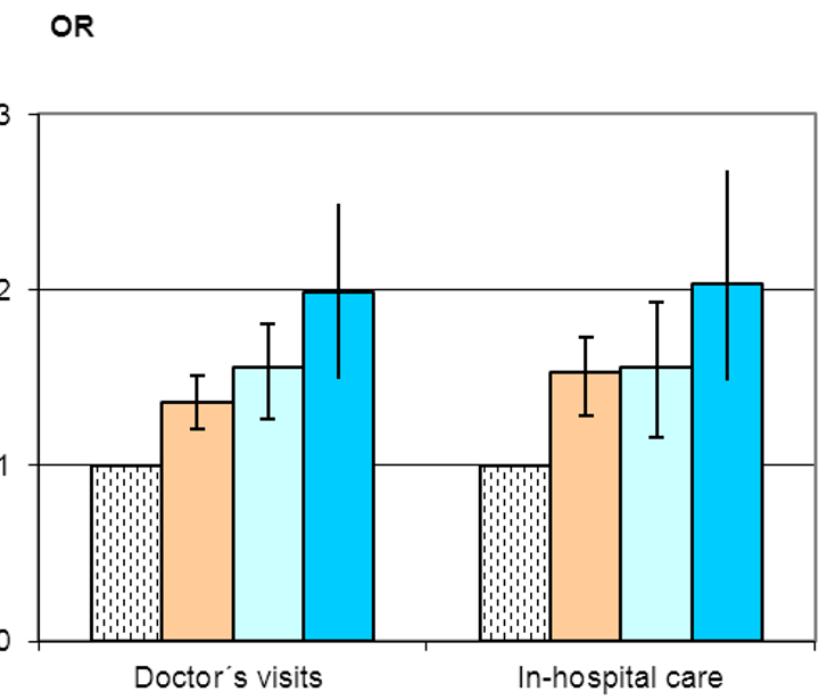

\begin{tabular}{|l|}
\hline QNo unfavourable \\
parental behavioral \\
factor \\
वOne unfavourable \\
parental behavioral \\
factor \\
पTwo unfavourable \\
parental behavioral \\
factors \\
Three unfavourable \\
parental behavioral \\
factors \\
\hline
\end{tabular}

Figure 3 Odds ratios and $95 \%$ confidence intervals for various types of medical care consumption (doctor's visits and in-hospital care) in 8-month-old children in Malmö, Sweden, by presence of one, two or three unfavorable parental lifestyle factors (maternal smoking during pregnancy, secondhand tobacco smoke during 0-4 weeks of age, and duration of exclusive breastfeeding $<4$ months). The reference group comprised children who were not exposed to maternal smoking during pregnancy or secondhand tobacco smoke during 0-4 weeks of age, and who were exclusively breastfed $\geq 4$ months 
Table 4 Odds ratios $(95 \% \mathrm{Cl})$ of doctoral visits and in-hospital stay in relation to maternal educational level

\begin{tabular}{|c|c|c|c|c|c|c|}
\hline & \multicolumn{3}{|c|}{ Doctoral visit beside the regular CHC visits during the last 8 months } & \multicolumn{3}{|c|}{ In-hospital stay during the last 8 months } \\
\hline & $\begin{array}{l}\text { Model 1 }{ }^{\mathrm{b}} \text { OR } \\
(95 \% \mathrm{Cl})^{\mathrm{a}}\end{array}$ & $\begin{array}{l}\text { Model 2c OR } \\
(95 \% \mathrm{Cl})^{\mathrm{a}}\end{array}$ & $\begin{array}{l}\text { Model 3d OR } \\
(95 \% \mathrm{CI})^{\mathrm{a}}\end{array}$ & $\begin{array}{l}\text { Model 1 } 1^{\mathrm{b}} \text { OR } \\
(95 \% \mathrm{Cl})^{\mathrm{a}}\end{array}$ & $\begin{array}{l}\text { Model 2c OR } \\
(95 \% \mathrm{Cl})^{\mathrm{a}}\end{array}$ & $\begin{array}{l}\text { Model 3d OR } \\
(95 \% \mathrm{Cl})^{\mathrm{a}}\end{array}$ \\
\hline \multicolumn{7}{|c|}{ Maternal educational level } \\
\hline$\geq 12$ years & 1.0 & 1.0 & 1.0 & 1.0 & 1.0 & 1.0 \\
\hline 10-12 years & $1.27(1.15,1.41)$ & $1.26(1.14,1.40)$ & $1.14(1.02,1.29)$ & $1.07(0.93,1.24)$ & $1.07(0.93,1.24)$ & $1.04(0.88,1.25)$ \\
\hline$\leq 9$ years & $1.28(1.09,1.50)$ & $1.25(1.06,1.48)$ & $1.11(0.91,1.35)$ & $1.34(1.08,1.66)$ & $1.33(1.06,1.65)$ & $1.16(0.89,1.51)$ \\
\hline \multicolumn{7}{|c|}{${ }^{\mathrm{a} O R}$ odds ratio; $\mathrm{Cl}$ Confidence interval } \\
\hline \multicolumn{7}{|c|}{${ }^{\mathrm{b}}$ Adjusted for year, sex, parents country of birth, low birth weight and number of children at home } \\
\hline \multicolumn{7}{|c|}{ 'Model 1 with additional adjustment for low emotional support and low practical support } \\
\hline a & 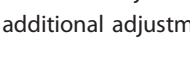 & ternal smoking du & ncy, secondhand & & & \\
\hline
\end{tabular}

smoking and environmental smoking have also been shown to be associated with wheeze in infancy [7]. A recent review showed that secondhand tobacco smoke was associated with both the onset and severity of asthma, as well as respiratory and middle ear infections among children [27]. The latter effect has been shown to be of particular importance during the first two years of life [1].

Earlier studies have shown that parental behavior is influenced by material resources and knowledge of favorable life styles [1]. Similarly, in the present study, children with lower educated mothers also more often lacked the protective advantages of breastfeeding. The most common problem with breastfeeding among lesseducated mothers was insufficient breast milk, which in turn was the breastfeeding problem associated with the lowest proportion of exclusive breastfeeding $\geq 4$ months. Knowledge about the type and occurrence of the various problems related to duration of breastfeeding is important in order to allow the construction of effective breastfeeding promotion programs.

Low emotional and practical support have previously been shown to be associated with health care seeking $[28,29]$. For example, a recent American study showed that children whose parents experienced low emotional support had higher odds for having paid visits to primary care with the child [28]. Poor maternal psychosocial functioning may influence the child's psychosocial and physical health both directly, by inhibiting the mother's ability to care for the child, and also indirectly through her limited personal resources to help her child by turning to a physician for assistance [29].

Certain methodological issues need to be addressed. First, about two thirds (65\%) of the parents who received the study questionnaire responded to it. An earlier study showed only small differences between participants and the general population with regard to the parental educational level, but with an underrepresentation of children whose parents were born outside Sweden [17]. Such an underrepresentation might affect absolute descriptive measures such as prevalences and proportions. However, when studying associations, it is more important that the relation between exposure and disease is similar for those who participate in the study, and those who are theoretically eligible for the study, including those who do not participate, rather than strict criteria of representativity [30]. The likelihood of such selection bias in a given study is often assessed by subjective reasoning. Second, self-reported data on parental behavioral factors is a potential source of bias. A recent review found a tendency to underestimate selfreported smoking, especially when smoking is seen as undesirable, such as during pregnancy [31]. Such an underestimation would lead to a dilution of the true associations. However, there are studies that have validated questionnaire information on presence of maternal smoking through blood samples measuring cotinine and thiocyanate in cord serum, reporting good agreement between high and low levels of biomarkers and daily and non-smoking mothers [32]. Self-reported length of breastfeeding is another potential source of bias. Previous studies on the validity of self-reported breast-feeding have been made [33,34]. A review on the validity and reliability of maternal recall of breastfeeding practice concluded that maternal recall is a valid and reliable estimate of breastfeeding duration, especially when the duration of breastfeeding is recalled after a shorter period ( $\leq 3$ years). However, validity and reliability of maternal recall for the age at introduction of food and fluids other than breast milk was less satisfactory [34]. Thus, there might be some recall error with regard to self-reported length of breastfeeding in the present study. Self-reported visits to medical care might be another potential source of bias. An American study, of self-reported information about children's hospitalizations and emergency visits, showed that parents had good recall information over the first 3 years of a child's life [35]. Although some degree of recall error cannot be ruled out, it would, if anything, most likely be of a nonsystematic nature, thus attenuating the true association 
between maternal educational level and medical care consumption. Third, we use maternal educational level as a measure of socioeconomic position (SEP). There are also other well-known measures of SEP such as parental occupational level and income that could be used, but, unfortunately, we do not have information on these other measures of SEP.

In conclusion, the results show that children with lesseducated mothers were exposed to more health risks, fewer health-promoting factors, worse social support and had a higher medical care consumption than children with higher-educated mothers. Furthermore, the differences in child medical care consumption by maternal educational level emphasize the notion that children's health seems to be influenced by the characteristics of the families into which they are born. Thus, improving children's health calls for policies that target the parent's health-related behaviors and social support.

\section{Acknowledgements}

This study was financed by the Region Skåne, by ALF government Grants Dnr M 2008/1592 (Maria Rosvall) and Dnr M 2007/1656 (Martin Lindström) and the Swedish Research Council Linnaeus Centre for Economic demography (VR 79).

\section{Author details}

'Department of Clinical Sciences, Malmö, Social Medicine and Health Policy, Lund University, S-205 02 Malmö, Sweden. ${ }^{2}$ Region Skåne, Malmo, Sweden.

\section{Authors' contributions}

EM and MR have contributed to the conception of the work, the analysis of the data, the interpretation and the discussion of the results, the drafting, writing and revision of the content. $\mathrm{KH}$ has contributed to the interpretation and the discussion of the results, the writing, and revision of the content. $\mathrm{ML}$ and $\mathrm{MK}$ have contributed to the interpretation and the discussion of the results.

\section{Declaration of conflicting interests}

The authors declare that they have no competing interests.

Received: 19 May 2011 Accepted: 24 November 2011

Published: 24 November 2011

\section{References}

1. National board of health and welfare. Public Health Report 2009. [http:// www.socialstyrelsen.se/publikationer2009/2009-126-71], (in Swedish).

2. Sundelin C: Socioekonomiska faktorers betydelse för barns hälsa och utveckling. The influence of socioeconomic factors on child health and development. Socialmedicinsk tidskrift 1995, 8:320-324, (In Swedish).

3. Ohälsa och sjukvård: 1980-2005, Statistics Sweden 2006. Report no.113, Stockholm, Sweden .

4. Cooper H, Smaje C, Arber S: Use of health services by children and young people according to ethnicity and social class: secondary analysis of a national survey. BMJ 1998, 317:1047-1051.

5. Irwin LG, Siddiqi A, Hertzman C: Early Child Development: a powerful equalizer. World Health Organizations Commission on social determinants of health 2007., Final Report.

6. Bråbäck L, Hjern A, Rasmussen F: Social class in asthma and allergic rhinitis: a national cohort study over three decades. Eur Respir J 2005, 26:1064-1068.

7. Strachan DP, Cook DG: Health effects of passive smoking.1. Parental smoking and lower respiratory illness in infancy and early childhood. Thorax 1997, 52:905-914.
8. Wold AE, Adlerberth I: Breastfeeding and the intestinal Microflora of the infant-Implications for protection against infectious diseases. Adv Exp Med Biol 2000, 478:77-93.

9. BAMSE projektet går vidare. Vårdal Nytt Nr 1 2003. [http://vardal.orbelon. com/vnytt/1-03/art06.html], (in Swedish).

10. Martin RM, Gunnell D, Owen CG, Smith GD: Breast-feeding and Childhood cancer: a systematic review with metaanalysis. Int J Cancer 2005, 117:1020-1031.

11. Angelsen NK, Vik T, Jacobsen G, Bakketeig LS: Breast feeding and cognitive development at age 1 and 5 years. Arch Dis Child 2001, 85:183-188.

12. Wright RJ: Epidemiology of stress and asthma: from constricting communities and fragile families to epigenetics. Immunol Allergy Clin North Am 2011, 31:19-39.

13. Koller D, Mielck A: Regional and social differences concerning overweight, participation in health check-ups and vaccination. Analysis of data from a whole birth cohort of 6-year old children in a prosperous German city. BMC Public Health 2009, 9:43.

14. Bremberg S: Sociala skillnader i ohälsa bland barn och ungdom i Sverige. (Social differences in ill-health among children and adolescents in Sweden). Stockholm: Swedish National Institute of Public Health; 2002.

15. [http://www.malmo.se/Kommun-politik/Om-oss/Statistik-om-Malmo.html], (in Swedish).

16. Magnusson $M$, Blennow $M$, Hagelin $E$, Sundelin C: Barnhälsovård- att främja barns hälsa. Stockholm: Liber AB; 2009, (in Swedish).

17. Rosvall M, Falck S, Moghaddassi M, Köhler M, Östergren P-O: Rapport 2007: Barns hälsa och levnadsförhållanden. Socialmedicinska Enheten Malmö: Region Skåne; 2007, (in Swedish).

18. Roberts H, Smith SJ, Bryce C: Children at risk? Safety as a social value. Buckingham: Oxford University Press; 1995.

19. Hjern A, Haglund B, Rosen M: Socioeconomic differences in use of medical care and antibiotics among schoolchildren in Sweden. Eur J Public Health 2001, 11:280-283.

20. Hjern A, Haglund B, Rasmussen F, Rosen M: Socio-economic differences in day care arrangements and use of medical care and antibiotics in Swedish preschool children. Acta Paediatr 2000, 89:1250-6.

21. Mangrio E, Wremp A, Moghaddassi M, Merlo J, Bramhagen AC, Rosvall M: Antibiotic use among 8-month-old children in Malmö, Sweden-in relation to child characteristics and parental sociodemographic, psychosocial and lifestyle factors. BMC Pediatr 2009, 9:31.

22. National board of Health and Welfare. Amning och Föräldrars Rökvanor 2008. [http://www.socialstyrelsen.se/publikationer2010/2010-8-2], (in Swedish).

23. Mangrio $E$, Lindström M, Rosvall M: Early life factors and being overweight at 4 years of age among children in Malmö, Sweden. BMC Public Health 2010, 10:764.

24. Chung KC, Kowalski CP, Kim HM, Buchman SR: Maternal cigarette smoking during pregnancy and the risk of having a child with cleft lip/palate. Plast Reconst Surg 2000, 105:485-491.

25. Shenassa ED, Brown MJ: Maternal smoking and infantile gastrointestinal dysregulation: the case of colic. Pediatric 2004, 114:497-505.

26. Sorensen HT, Labouriau R, Jensen ES, Mortensen PB, Schonheyder HC: Fetal growth, maternal prenatal smoking, and risk of invasive meningococcal disease: a nationwide case-control study. Int J Epidemiol 2004, 33:816-820.

27. Wigle DT, Arbuckle TE, Turner MC, Berube A, Yang Q, Liu S, Krewski D: Epidemiologic evidence of relationships between reproductive and child health outcomes and environmental chemical contaminants. J Toxicol Environ Health B Crit Rev 2008, 11:373-517.

28. Raphael JL, Zhang Y, Liu H, Giardino AP: Parenting stress in US families: implications for pediatric health care utilization. Child Care Health Dev 2010, 36:216-224.

29. Janicke DM, Finney JW, Riley AW: Children's health care use: A prospective investigation of factors related to care-seeking. Med care 2001, 39:990-1001.

30. Rothman K, Greeenland S: Precision and validity in epidemiological studies. In Modern Epidemiology. Edited by: Rothman K, Greenland S. Philadelphia: Lippincott-Raven; 1998:.

31. Gorber SC, Schofield-Hurwitz S, Hardt J, Levasseur G, Tremblay M: The accuracy of selfreported smoking: a systematic review of the relationship between self reported and cotinine-assessed smoking status. Nicotine Tob Res 2009, 11:12-24. 
32. Nafstad P, Kongerud J, Botten G, Urdal P, Silsand T, Pedersen BS, Jaakkola JJ: Fetal exposure to tobacco smoke products: a comparison between selfreported maternal smoking and concentrations of cotinine and thiocyanate in cord serum. Acta Ostet Gynecol Scand 1996, 75:902-907.

33. Troy LM, Michels KB, Hunter DJ, Spiegelman D, Manson JE, Colditz GA, et al: Self-reported birthweight and history of having been breastfed among younger women: an assessment of validity. Int J Epidemiol 1996, 25:122-127.

34. Li R, Scanlon KS, Serdula MK: The validity and reliability of maternal recall of breastfeeding practice. Nutr Rev 2005, 63:103-110.

35. D'Souza Vazirani D, Minkovitz CS, Strobino DM: Validity of maternal report of acute health care use for children younger than 3 years. Arch Pediatr Adoclsc Med 2005, 159:167-172.

\section{Pre-publication history}

The pre-publication history for this paper can be accessed here: http://www.biomedcentral.com/1471-2458/11/891/prepub

doi:10.1186/1471-2458-11-891

Cite this article as: Mangrio et al:: Maternal educational level, parental preventive behavior, risk behavior, social support and medical care consumption in 8-month-old children in Malmö, Sweden. BMC Public Health 2011 11:891.

\section{Submit your next manuscript to BioMed Central and take full advantage of:}

- Convenient online submission

- Thorough peer review

- No space constraints or color figure charges

- Immediate publication on acceptance

- Inclusion in PubMed, CAS, Scopus and Google Scholar

- Research which is freely available for redistribution

Submit your manuscript at www.biomedcentral.com/submit 